\title{
PENGARUH PROGRESSIVE MUSCLE RELAXATION TERHADAP SKALA NYERI PADA PASIEN POST SECTIO CAESARIA
}

\author{
Asri Wiwi Maryati, Cucu Rokayah*, Yeti Herawati \\ Program Studi Sarjana Keperawatan, STIKes Dharma Husada Bandung, Jl. Terusan Jakarta No.75, Cicaheum, \\ Kec. Kiaracondong, Kota Bandung, Jawa Barat, Indonesia 40282 \\ *cucurokayah611@gmail.com
}

\begin{abstract}
ABSTRAK
Banyaknya ibu post section dapat menimbulkan masalah pada luka sayatan di area abdomen yaitu nyeri. Ibu paska operasi Sectio Caesaria merasakan nyeri yang lebih tinggi dibandingkan dengan persalinan secara pervaginam sehingga kebutuhan ibu akan mobilisasi, perawatan diri dan bayinya, serta pemberian ASI kerapkali terganggu. Penelitian ini bertujuan untuk mengetahui pengaruh Progressive Muscle Relaxation (PMR) terhadap skala nyeri pada pasien post sectio caesaria di RSKIA Kota Bandung. Jenis penelitian ini berupa quasi eksperimen dengan metode pre test dan post test. Populasi penelitian sebanyak 34 pasien dibagi menjadi dua kelompok yaitu kelompok kontrol dan intervensi masing-masing 17 pasien. Metode pengumpulan data dengan carapurposive sampling. Instrumen penelitian ini menggunakan skala NRS (Numeric Rating Scale). Hasil penelitian menunjukkan skala nyeri sebelum dilakukan teknik PMR pada kelompok kontrol berada pada tingkat nyeri sedang sebanyak 7 responden $(41.2 \%)$ dan pada kelompok intervensi berada pada tingkat sedang sebanyak 14 orang $(82.4 \%)$. Skala nyeri sesudah dilakukan teknik PMR pada kelompok kontrol berada pada tingkat nyeri sedang sebanyak 10 orang $(58.8 \%)$ dan pada kelompok intervensi pada tingkat sedang sebanyak 11 orang (64.7\%).Pengaruh PMR pada kelompok kontrol memiliki nilai p-value 0.059. Pengaruh teknik PMR pada kelompok intervensi memiliki nilai p-value 0.001 sehingga terdapat pengaruh Progressive Muscle Relaxation pada pasien post sectio caesaria di RSKIA Kota Bandung. Pengaruh teknik PMR terhadap skala nyeri memiliki nilai p-value 0.030 sehingga dapat disimpulkan terdapat pengaruh Progressive Muscle Relaxation pada pasien post section caesaria di RSKIA Kota Bandung.
\end{abstract}

Kata kunci: nyeri, progressive muscle relaxation, sectio caesaria

\section{THE EFFECT OF PROGRESSIVE MUSCLE RELAXATION ON THE SCALE OF PAIN IN POST SECTIO CAESARIA}

\begin{abstract}
Section caesare caused by problems in wound incisions in the abdominal area, namely pain. Respondent with section caesaria has a higher pain scale compared to respondents with normal delivery, so that the mother's need for mobilization, self-care and her baby, and breastfeeding are often disrupted. This study aims to determine the effect of Progressive Muscle Relaxation (PMR) on the scale of pain in post sectio caesaria patients at RSKIA in Bandung. This type of research is quasiexperimental. The study population was 34 patients divided into two groups, namely the control and intervention groups. This type of research is quasi-experimental with the pre-test and post-test methods. The instrument of this study uses the NRS (Numeric Rating Scale).The results showed the scale of pain before the PMR technique in the control group was at the level of moderate pain as many as 7 respondents (41.2\%) and the intervention group was at a moderate level of 14 people (82.4\%). The scale of pain after the PMR technique in the control group was at a moderate level of pain of 10 people (58.8\%) and in the intervention group at a moderate level of 11 people (64.7\%). The effect of PMR techniques on the control group has a p-value of 0.059. The effect of PMR technique on the intervention group has a p-value of 0.001 so that there is an effect of Progressive Muscle Relaxation in post sectio caesaria patients at RSKIA Bandung City. The effect of PMR technique on pain scale has a p-value of 0.030 so it can be concluded that there is an effect of Progressive Muscle Relaxation in post sectio caesaria patients at RSKIA Bandung City.It is hoped that the results of this study can be used as guidelines for nurses' interventions that can be taught to patients and families as a patient companion in conducting this PMR technique.
\end{abstract}

Keywords: pain, progressive muscle relaxation, sectio caesaria 


\section{PENDAHULUAN}

Komplikasi masa kehamilan, persalinan dan nifas merupakan masalah kesehatan yang penting, jika tidak ditanggulangi bisa menyebabkan kematian ibu yang tinggi. Tragedi yang mencemaskan dalam proses reproduksi salah satunya kematian yang terjadi pada ibu (Depkes, 2013). Berdasarkan survey pada tahun 2013 AKI didunia sebesar 210 kematian per 100.000 kelahiran hidup, sedangkan di negara berkembang 14 kali lebih tinggi bila dibandingkan negara maju, yaitu 230 per 100.000 kelahiran (WHO, 2014). Angka Kematian Ibu di Indonesia tergolong tinggi jika dibandingkan dengan Negaranegara ASEAN lainnya. AKI pada tahun 2013 di Indonesia 190/100.000 kelahiran hidup, Malaysia 29/100.000 kelahiran hidup, Vietnam 49/100.000 kelahiran hidup, Singapore 6/100.000 kelahiran hidup, Fhilipina 120/100.000 kelahiran hidup, Thailand 26/100.000 kelahiran hidup (WHO, 2014). AKI di Indonesia pada tahun 2015 sebanyak 4.999 kasus, pada tahun 2016 menjadi 4912 dan di tahun 2017 (semester I) sebanyak 1712 kasus (Departemen Kesehatan, 2017). Angka kejadian Sectio Caesaria di Jawa Barat adalah 2.256 jiwa (Kementrian Kesehatan RI, 2018).

Sectio caesaria merupakan salah satu cara yang digunakan dibidang kesehatan untuk membantu persalinan ketika ada masalah tak terduga terjadi selama persalinan, seperti faktor dari ibu yaitu panggul yang sempit, faktor dari janin yang letaknya lintang, tidak cukup ruang bagi janin untuk melalui vagina, dan kelainan pada janin seperti berat badan janin melebihi 4000 gram (National Institute of Health, 2012). Sectio caesaria juga mempunyai dampak negatif diantaranya adanya rasa nyeri, kelemahan, gangguan integritas kulit, nutrisi kurang dari kebutuhan, resiko infeksi dan sulit tidur, tetapi dampak yang paling sering muncul dirasakan oleh klien post sectio caesaria adalah rasa nyeri akibat efek pembedahan (Solehati \& Kosasih, 2015)

Pengendalian nyeri dapat dilakukan secara farmakologi dan non farmakologi (Potter \&Perry, 2010). Teknik farmakologi adalah cara yang paling efektif untuk menghilangkan nyeri terutama untuk nyeri yang sangat hebat yang berlangsung selama berjam-jam atau bahkan berhari-hari (Smeltzer, 2010). Metode non farmakologi bukan merupakan pengganti untuk obat-obatan, tindakan tersebut diperlukan untuk mempersingkat episode nyeri yang berlangsung hanya beberapa detik atau menit. Saat terjadi nyeri hebat mengkombinasikan metode non farmakologi dengan obat-obatan merupakan cara yang paling efektif untuk mengontrol nyeri. Pengendalian nyeri non-farmakologi menjadi lebih murah, simpel, efektif dan tanpa efek yang merugikan (Potter \& Perry, 2010).

Ada beberapa teknik relaksasi untuk mengurangi nyeri yaitu relaksasi nafas dalam, relaksasi genggam jari dan teknik progressive muscle relaxation.PMR bermanfaat untuk menurunkan resistensi perifer dan menaikkan elastisitas pembuluh darah.otot-otot dan peredaran darah akan lebih sempurna dalam mengambil dan mengedarkan oksigen serta relaksasi otot progresif dapat bersifat vasodilator yang efeknya memperlebar pembuluh darah dan dapat menurunkan tekanan darah secara langsung serta dapat mengurangi rasa nyeri. PMR ini menjadi metode relaksasi termurah, tidak memerlukan imajinasi, tidak ada efek samping, mudah dilakukan, membuat tubuh dan pikiran terasa tenang dan rileks (Maryam, 2010).Tujuan penelitian ini yaitu mengetahui pengaruh Progressive Muscle Relaxation terhadap skala nyeri pada klien post sectio caesarea di RSKIA Kota Bandung. Penelitian ini penting dilakukan untuk menurunkan nyeri post sectio caesare sehingga ibu- ibu bisa lebih fokus terhadap perawatan bayinya.

\section{METODE}

Penelitian ini merupakan penelitian quasi eksperimen dengan jenis penelitian observasional analitik dan desain menggunakan studi potong lintang (cross sectional). Rancangan ini menggunakan satu kelompok sampel yang diobservasi sebanyak dua kali, yaitu observasi sebelum eksperimen disebutpretest, dan observasi sesudah eksperimen disebut post test.

Desain ini terdapat dua kelompok yang dipilih secara random kemudian diberi pretest untuk mengetahui adakah perbedaan kelompok intervensi dan kelompok kontrol. Tempat penelitian di RSKIA Kota Bandung dan dilakukan pada bulan Juli 2019. Populasi dalam penelitian ini adalah pasien post sectio caesaria. Sampel pasien post Sectio caesaria 
sebanyak 17 orang untuk kelompok intervensi dan 17 orang untuk kelompok kontrol yang sesuai dengan kriteria inklusi dan eksklusi.

Kriteria inklusi kelompok intevensi :Klien dengan nyeri ringan sampai berat, Belum pernah melakukan terapi PMR, Post sectio caesarea POD 2- 3, Post sectio caesarea dengan anastesi spinal, sedangkan Kriteria Eklusi kelompok intervensi : Post sectio caesarea dengan komplikasi. Kriteria inklusi kelompok control :Klien dengan nyeri ringan sampai berat, Post Sectio Caesaria dengan jenis anastesi total, Belum pernah melakukan terapi PMR. Kriteria Eklusi kelompok control
:Post sectio caesarea dengan komplikasi Instrumen yang digunakan dalam penelitian ini adalah NRS (Numeric Rating Scale).

\section{HASIL}

Hasil penelitian yang telah dilakukan kepada 34 responden selama 6 kali pertemuan selama 2 minggu yang dilakukan oleh peneliti sendiri mengenai "Pengaruh Progressive Muscle Relaxation pada pasien Post Sectio Caesaria di RSKIA Kota Bandung" dapat dilihat pada tabel berikut:

Tabel 1.

Skala nyeri pasien post sectio caesaria pada sebelum dilakukan progressive muscle relaxation pada kelompok kontrol dan intervensi $(n=17 ; n=17)$

\begin{tabular}{ccccc}
\hline Kategori & \multicolumn{2}{c}{ Kontrol } & \multicolumn{3}{c}{ Intervensi } \\
\cline { 2 - 5 } & $\mathrm{f}$ & $\%$ & $\mathrm{f}$ & $\%$ \\
\hline Nyeri ringan & 3 & 17,6 & 6 & 35,3 \\
\hline Nyeri sedang & 10 & 58.8 & 11 & 64,7 \\
\hline Nyeri berat & 4 & 23,5 & 0 & 0
\end{tabular}

Berdasarkan tabel 1, skala nyeri pasien post section caesarea sebelum dilakukan progressive muscle relaxation berada pada kategori nyeri sedang sebanyak 7 orang ( 41.2
$\%)$ pada kelompok control dan pada kelompok intervensi berada pada kategori nyeri sedang sebanyak 14 orang $(82,4 \%)$

Tabel 2.

Skala nyeri pasien post sectio caesaria sesudah dilakukan progressive muscle relaxation pada kelompok kontrol dan intervensi $(n=17 ; n=17)$

\begin{tabular}{clrcc}
\hline Kategori & \multicolumn{2}{c}{ Kontrol } & \multicolumn{3}{c}{ Intervensi } \\
\cline { 2 - 5 } & $\mathrm{f}$ & \multicolumn{1}{c}{$\%$} & $\mathrm{f}$ & $\%$ \\
\hline Nyeri ringan & 5 & 29,4 & 0 & 0 \\
\hline Nyeri sedang & 7 & 41,2 & 14 & 82,4 \\
\hline Nyeri berat & 5 & 29,4 & 3 & 17,6 \\
\hline $\begin{array}{l}\text { Berdasarkan tabel } \\
\text { section caesarea sesudah dilakukan progressive }\end{array}$ & $\begin{array}{l}\text { kelompok } \\
\text { muscle relaxation berada pada kategori nyeri }\end{array}$ & $\begin{array}{l}\text { control dan } \\
\text { intervensi berada pada kategori nyeri sedang } \\
\text { sebanyak 14 orang }(82,4 \%)\end{array}$
\end{tabular}

Tabel 3.

Pengaruh progressive muscle relaxation pada pasien post sectio caesaria kelompok kontrol $(\mathrm{n}=17)$

\begin{tabular}{ccc}
\hline Pengukuran & median & P value \\
Pre & 6.00 & 0,001 \\
\hline Post & 4.00 & \\
\hline $\begin{array}{l}\text { Berdasarkan tabel } 3 \text { pengaruh progressive } \\
\text { muscle relaxation pada pasien post section }\end{array}$ & $\begin{array}{l}\text { caesarea pada kelompok control dengan nilai } \\
\text { p-value } 0.001 \text { lebih kecil dari nilai alpha }\end{array}$
\end{tabular}


Tabel 4.

Pengaruh Progressive Muscle Relaxation pada pasien post Sectio Caesaria kelompok intervensi $(\mathrm{n}=17)$

\begin{tabular}{ccc}
\hline Pengukuran & median & P value \\
Pre & 6.00 & 0,059 \\
\hline Post & 6.00 & \\
\hline $\begin{array}{c}\text { Berdasarkan tabel } 4 \text { pengaruh progressive } \\
\text { muscle relaxation pada pasien post section }\end{array}$ & $\begin{array}{l}\text { caesarea pada kelompok control dengan nilai } \\
\text { p-value 0.059 lebih besar dari nilai alpha }\end{array}$
\end{tabular}

Tabel 5.

PengaruhProgressive Muscle Relaxation terhadap skala nyeri pasien post Sectio Caesaria pada kelompok kontrol dan intervensi $(\mathrm{n}=17 ; \mathrm{n}=17)$

\begin{tabular}{|c|c|c|c|}
\hline \multirow[t]{2}{*}{ Pengukuran } & \multicolumn{2}{|c|}{ median } & $P$ value \\
\hline & Kontrol & Intervensi & \\
\hline Pre & 6.00 & 6.00 & 0,030 \\
\hline Post & 4.00 & 6.00 & \\
\hline
\end{tabular}

\section{PEMBAHASAN}

Nyeri menurut The International Association for The Study of pain adalah suatu ketidaknyamanan, bersifat subjektif, sensori dan pengalaman emosional yang dihubungkan dengan actual dan potensial untuk merusak jaringan atau digambarkan sebagai sesuatu yang merugikan (Solehati \& Kosasih, 2015). yeri yang dirasakan berdasarkan tabel 1 dapat terjadi karena sepanjang sistem spinotalamik impuls-impuls nyeri berjalan melintasi medulla spinalis, thalamus mentransmisikan informasi ke pusat yang lebih tinggi di otak, ketika stimulus nyeri sampai ke korteks serebral, maka otak akan menginterpretasikan kualitas nyeri. Bersamaan dengan seseorang menyadari nyeri maka reaksi fisiologis maupun psikologis mulai terjadi dimana reaksi fisiologis akan meningkatkan saraf simpatis yang menyebabkan ketegangan pada otot seseorang (Potter \& Perry, 2010). Nyeri ini dapat dipengaruhi oleh beberapa faktor yaitu usia, pendidikan, pekerjaan, jenis anastesi, paritas dan POD (Postoperative Day).

Berdasarkan tabel 2 dari hasil penelitian menunjukkan bahwa ada perubahan pada kelompok intervensi terdapat nyeri ringan sebanyak 6 orang.Hasil ini menunjukkan penurunan skala nyeri menjadi skala nyeri ringan pada kelompok intervensi.Penurunan nyeri ini dapat terjadi karena menurut soesmalijah, (2012) PMR juga bertujuan agar badan dapat rileks dengan mencoba merasakan otot-otot saat tegang dan kaku dengan mengencangkan dan melemaskan otot-otot yang tegang untuk membantu badan menjadi rileks dan menurunkan intensitas nyeri.
Hasil penelitian ini sesuai dengan teori yang mana pasien post sectio caesaria bisa menjadi lebih rileks sehingga dapat menurunkan tingkat nyeri secara perlahan. Hal ini terjadi karena gerakan-gerakan yang diberikan dapat memperlancar peredaran darah lebih efektif.

Berdasarkan tabel 3 Hasil uji statistik tersebut pasien post SC kelompok kontrol tidak mengalami penurunan skala nyeri. Tetapi responden mendapatkan injeksi analgesic asam mefenamat. Injeksi diberikan $3 \mathrm{x} /$ hari dengan ketentuan jam 08.00, 15.00 dan 21.00. Asam mefenamat menghambat sintesis prostlagandin. Prostlagandin merupakan senyawa kimia yang berperan sebagai mediator utama proses peradangan pada tubuh. Kadar prostlagandin yang menurun ini dapat meredakan peradangan dan nyeri sehingga pada saat dilakukan post test terlihat adanya penurunan skala nyeri dikarenakan efek obat analgesic masih terasa pada pasien, tetapi penurunan skala nyeri ini tidak signifikan karena hanya diberikan pengobatan secara farmakogis saja. Dapat disimpulkan bahwa nyeri yang dirasakan pasien post SC mengalami penurunan setiap hari jika diberikan terapi secara farmakologis. Tetapi penurunan skala nyeri yang dirasakan oleh kelompok kontrol tidak signifikan sehingga perlu penambahan terapi secara non farmakologis.

Berdasarkan tabel 4 uji statistik pada kelompok intervensi dengan uji wilcoxon didapatkan nilai $p$-value sebesar 0.001 , dapat disimpulkan bahwa terdapat pengaruh Progressive Muscle Relaxation tehadap skala 
nyeri pada pasien post Sectio caesaria di RSKIA Kota Bandung. Hasil analisis skala nyeri post SC kelompok intervensi, pada saat pre test memiliki nilai mean sebesar 6.00 dan pada saat post test 4.00. Hasil uji statistik menunjukkan bahwa terjadi penurunan skala nyeri pada kelompok intervensi.Penurunan skala nyeri pada kelompok intervensi dipengaruhi oleh perpaduan antara farmakologis dan non farmakologis yaitu terapi Progressive Muscle Relaxation.

Tujuan dari PMR ini adalah menurunkan nyeri secara non farmakologis, memberikan dan meningkatkan pengalaman subjektif bahwa ketegangan psikologis bisa direlaksasikan sehingga relaksasi akan menjadi kebiasaan seseorang berespon terhadap keadaan tertentu ketika otot tegang, dan dapat menurunkan stress psikologis (Fitria, 2014), karena gerakan yang telah diberikan secara perlahan membantu merilekskan sinap sinap saraf baik yang simpatis maupun parasimpatis, saraf yang rileks dapat menurunkan nyeri secara perlahan.

PMR dilakukan dengan cara meregangkan dan merilekskan otot secara sadar (Tyani, 2015). Karena gerakan yang telah diberikan secara perlahan membantu merilekskan sinap sinap saraf baik yang simpatis maupun parasimpatis, saraf yang rileks dapat menurunkan nyeri secara perlahan.Penelitian ini sesuai dengan penelitian yang dilakukan oleh Puspa Kirana Dewi et al pada tahun 2018 yang berjudul pengaruh Relaksasi Otot Progresif terhadap penurunan nyeri punggung bagian bawah ibu hamil trimester III, terapi ini terdapat pengaruh untuk menurunkan nyeri.

Berdasarkan tabel 5 pengaruh teknik Progressive Muscle Relaxation terhadap skala nyeri pasien post Sectio Caesaria didapatkan hasil bahwa nilai p-value 0.000 . Kesimpulannya bahwa Ha diterima terdapat pengaruh Progressive Muscle Relaxation terhadap nyeri pada pasien post sectio caesaria di RSKIA Kota Bandung.Pasien post sectio caesaria yang dilakukan teknik PMR mengalami penurunan skala nyeri tetapi tidak menghilangkan nyeri tersebut karena luka dari operasi sectio caesaria tersebut merupakan luka yang dibuat mulai dari lapisan perut sampai lapisan uterus yang penyembuhannya bertahap sehingga masih merasakan nyeri. Nyeri yang dirasakan ibu post sectio caesaria dapat dikendalikan dengan metode penatalaksanaan nyeri yang dilakukan peneliti pada penelitian ini. Progressive Muscle Relaxation merupakan terapi tambahan pada pasien yang telah menjalani operasi untuk meminimalkan tingkat rasa nyeri post operasi. Hasil ini sejalan dengan penelitian Livana, Daulima, dan Mustikasari (2018) bahwa PMR mampu menurunkan tanda dan gejala nyeri sehingga mampu menurunkan tingkat stres.

\section{SIMPULAN}

Berdasarkan hasil penelitian yang telah dilakukan kepada 34 responden selama 6 kali pertemuan selama 2 minggu yang dilakukan oleh peneliti mengenai "Pengaruh Progressive Muscle Relaxation pada pasien Post Sectio Caesaria di RSKIA Kota Bandung" terdapat kesimpulan yaitu: skala nyeri sebelum dilakukan teknik PMR pada kelompok kontrol berada pada tingkat nyeri sedang sebanyak 7 responden $(41.2 \%)$ sedangkan pada kelompok kontrol berada pada tingkat sedang sebanyak 14 orang (82.4\%). Skala nyeri sesudah dilakukan teknik PMR pada kelompok kontrol berada pada tingkat nyeri sedang sebanyak 10 orang $(58.8 \%)$ daan pada kelompok intervensi pada tingkat sedang sebanyak 11 orang $(64.7 \%)$

Pengaruh teknik PMR pada kelompok kontrol memiliki nilai $p$-value 0.059.Pengaruh teknik PMR pada kelompok intervensi memiliki nilai p-value 0.001 sehingga terdapat pengaruh Progressive Muscle Relaxation pada pasien post sectio caesaria di RSKIA Kota Bandung. Pengaruh teknik PMR terhadap skala nyeri memiliki nilai p-value 0.030 sehingga dapat disimpulkan terdapat pengaruh Progressive Muscle Relaxation pada pasien post section caesaria di RSKIA Kota Bandung

\section{DAFTAR PUSTAKA}

Departemen Kesehatan. (2017, 08 16). Inilah Capaian Kinerja Kemenkes RI Tahun 2015- 2017. Retrieved 08 16, 2017, from depkes.go.id: http://www.depkes.go.id/article/view/17 081700004/-inilah-capaian-kinerjakemenkes-ri-tahun-2015--2017.html

Fitria, C. N., \& Ambarwati, R. D. (2015). Efektifitas Teknik Relaksasi Progresif Terhadap Intensitas Nyeri Pasca Operasi Laparatomi. Diakeses dari 
https://journal.akpergshwng.ac.id. diunduh pada 31 Januari 2019

Livana, P. H., Daulima, N. H. C., \& Mustikasari, M. (2018). Relaksasi Otot Progresif Menurunkan Stres Keluarga yang Merawat Pasien Gangguan Jiwa. Jurnal Keperawatan Indonesia, 21(1), 51-59.

Maryam. (2010). buku panduan kader posbindu lansia. Jakarta timur: Trans Media Info.

Potter, P. A., \& Perry, A. G. (2010). Fundamental of Nursing. Singapore

Solehati, T., \& Kosasih, C. E. (2015). Relaksasi dalam Keperawatan Maternitas. Bandung: Refika Aditama.

WHO, 2014. Jumlah AKI di dunia 